Sains Malaysiana 47(9)(2018): 2157-2162

http://dx.doi.org/10.17576/jsm-2018-4709-25

\title{
Pengawalan Pertumbuhan Sebatian antara Logam Sambungan Pateri-Papan Litar Bercetak Menggunakan Salutan Nikel
}

(Controlling of Intermetallic Compound Solder Interconnection-Printed Circuit Board using Nickel Coating)

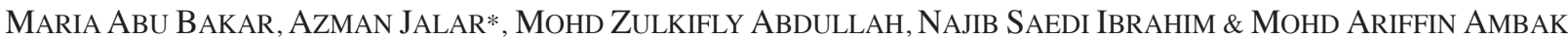

\begin{abstract}
ABSTRAK
Bahan aloi pateri dalam kumpulan $\mathrm{Sn}$-Ag-Cu (SAC) merupakan bahan pematerian yang bebas plumbum digunakan secara meluas dalam industri elektronik. Antarasambungan pateri bertindak untuk menghubungkan komponen elektronik pada papan litar bercetak ( $Р C B)$. РСB memainkan peranan yang penting dalam tindak balas pematerian dan mikrostruktur antarasambungan pateri-substrat seterusnya mempengaruhi kebolehharapan suatu sambungan pateri. Pes pateri Sn0.3Ag0.7Cu (SAC0307) dipaterikan pada tiga jenis PCB iaitu PCB tanpa salutan (PCB/Cu) sebagai sampel kawalan, $P C B$ dengan salutan timah ( $P C B / S n)$ dan PCB dengan salutan nikel (PCB/Ni). Kajian ini bertujuan untuk mengkaji kesan salutan permukaan PCB ke atas pertumbuhan sebatian antara logam (IMC) selepas uji kaji penuaan sesuhu yang berbeza selama 1000 jam. Keputusan menunjukkan purata ketebalan lapisan IMC 5.7 um serta kadar pertumbuhan lapisan IMC yang paling rendah adalah selari dengan tenaga pengaktifan tertinggi dengan salutan Ni iaitu $41 \mathrm{~kJ} / \mathrm{mol}$ berbanding $\mathrm{PCB} / \mathrm{Cu}$ dan $\mathrm{PCB} / \mathrm{Sn}$. Ini bermakna salutan Ni pada PCB mampu mengawal pertumbuhan IMC sehingga lebih kurang $40 \%$ berbanding salutan Sn dan tanpa salutan.
\end{abstract}

Kata kunci: Antarasambungan pateri; salutan Ni; sebatian antara logam; Sn-Ag-Cu; tenaga pengaktifan

\section{ABSTRACT}

Solder alloy materials in $\mathrm{Sn}-\mathrm{Ag}-\mathrm{Cu}(\mathrm{SAC})$ group is a lead free soldering materials which widely used in the electronics industry. Solder interconnection act to attach electronic components to printed circuit boards (PCBS). PCB plays an important role in soldering reactions and microstructure solder interconnection-substrate which further affects the reliability of a solder joint. Solder paste of $\mathrm{SnO}$.3Ag0.7Cu (SAC0307) is soldered on three types of PCB ie PCB without coating $(P C B / C u)$ as controlled sample, $P C B$ with tin coating $(P C B / S n)$ and $P C B$ with nickel coating $(P C B / N i)$. The purpose of this study was to investigate the effect of $P C B$ surface coating on the growth of intermetallic compound (IMC) after different aging tests for $1000 \mathrm{~h}$. The results showed that the average IMC layer thickness $5.7 \mu \mathrm{m}$ together with lowest $I M C$ layer growth rate is in line with highest activation energy, $41 \mathrm{~kJ} / \mathrm{mol}$ with the usage of Ni coating as compared to $P C B / C u$ and $P C B / S n$. This means that the Ni coating on PCB is able to control IMC growth up to $40 \%$ compared to Sn coating and non-coating.

Keywords: Activation energy; intermetallic compound; Ni coating; Sn-Ag-Cu; solder interconnection

\section{PENGENALAN}

Papan litar bercetak (PCB) telah digunakan secara meluas sebagai substrat dalam pempakejan elektronik. Substrat memainkan peranan yang sangat penting dalam interaksi pateri dalam pematerian. Kebiasaannya, substrat iaitu pad logam kuprum $(\mathrm{Cu})$ digunakan pada PCB yang merupakan tempat untuk menghubungkan antara komponen elektronik dengan PCB tersebut menerusi antarasambungan pateri. Walaupun logam $\mathrm{Cu}$ merupakan substrat yang biasa digunakan bagi sambungan pateri, namun begitu, logam $\mathrm{Cu}$ ini mudah teroksida dalam keadaan atmosfera (Bui et al. 2010). Maka salutan permukaan diperlukan untuk mengekalkan kekonduksian $\mathrm{Cu}$ (Lin et al. 2016). Lantaran itu, pelbagai jenis salutan permukaan diperkenalkan bagi menyalut permukaan pad logam. Salutan permukaan memainkan peranan yang penting, antaranya ialah untuk meningkatkan kebolehbasahan dan tindak balas antara pateri-substrat. Terdapat pelbagai jenis salutan permukaan diaplikasikan pada PCB. Contohnya seperti organic solderability preservative (OSP), nickel-aurum ( $\mathrm{NiAu})$, electroless nickel immersion gold (ENiG), electroless nickel electroless palladium immersion gold (ENEPIG), immersion tin (ImSn) dan immersion silver (ImAg) (Chen et al. 2007; Kao \& Chen 2018; Yan et al. 2017; Yi et al. 2018). Pelbagai jenis fungsi salutan permukaan, antaranya ialah lapisan aurum (Au) dapat memberikan rintangan kepada pengoksidaan dan kebolehbasahan yang baik antara pateri dan pad (Sundelin et al. 2006). Selain itu, terdapat jenis salutan permukaan bertujuan untuk mengelakkan resapan $\mathrm{Cu}$ ke dalam pateri bagi mengurangan pertumbuhan sebatian antara logam (IMC) yang berlebihan (Yoon et al. 2015). Hal ini adalah kerana pertumbuhan IMC secara berlebihan akan menyebabkan kerapuhan antarasambungan pateri yang seterusnya 
akan mengakibatkan kegagalan sambungan pateri. Kebolehharapan sambungan pateri yang mengurang dalam jangka masa panjang merupakan indikasi penting bahawa alat peranti mudah alih akan rosak (Nishikawa \& Iwata 2015). Maka daripada itu, kebanyakan pengkaji akan memberi fokus terhadap IMC (Zhang \& Zhang 2011) untuk memahami dan mengubah suai lapisan IMC bagi meningkatkan kebolehharapan sambungan pateri (Fallahi et al. 2012). Pemerhatian dilakukan untuk mengetahui morfologi IMC yang tumbuh daripada segi bentuk, saiz dan komposisi. Pembentukan IMC adalah dipengaruhi oleh pelbagai jenis faktor termasuklah kesan suhu, masa, salutan permukaan PCB dan penambahan unsur ke dalam aloi pateri. Chen dan Li (2004) telah melaporkan bahawa bentuk butiran yang lebih seragam dan ketebalan IMC yang lebih nipis didapati bagi sambungan pateri yang mengandungi antimoni (Sb) berbanding sambungan pateri tanpa unsur $\mathrm{Sb}$.

Salutan lapisan Au telah digunakan dalam industri elektronik yang bertujuan untuk melindungi permukaan pad $\mathrm{Cu}$ daripada teroksida (Lin \& Chen 2012). Lapisan oksida ini menjadi penghalang kepada proses kebasahan yang menyekat pateri untuk tersebar serta bertindak balas dengan substrat (Goncalves et al. 2015). Dalam kes pateri, kebolehbasahan ialah merujuk kepada keupayaan leburan pateri untuk bertindak balas pada antara muka substrat untuk membentuk IMC yang bertindak sebagai lapisan pelekat yang menyambungkan pateri dan substrat. Penyebaran pateri pada permukaan logam dasar adalah kompleks yang melibatkan proses fizik dan kimia iaitu resapan antara cecair dan pepejal, penukleusan dan disusuli oleh pembentukan dan pertumbuhan IMC pada antaramuka pateri yang menentukan kelakuan sistem logam pateri-logam dasar. Salutan permukaan adalah sangat penting terutamanya dalam tindak balas pematerian dan mikrostuktur antarasambungan pateri-substrat kerana ketebalan lapisan IMC, komposisi mikrostruktur, sifat mekanik dan kebolehharapan suatu sambungan pateri adalah sangat dipengaruhi oleh lapisan salutan permukaan (Kim et al. 2016). Kajian ini bertujuan untuk mengkaji pengaruh salutan permukaan PCB ke atas pembentukan sebatian IMC bahan pateri SAC0307 selepas didedahkan pada penuaan sesuhu yang berbeza selama 1000 jam. Kajian ini menggunakan $\mathrm{PCB} / \mathrm{Cu}$ iaitu $\mathrm{PCB}$ tanpa salutan permukaan digunakan sebagai sampel kawalan dan dua jenis salutan permukaan sebagai perbandingan iaitu salutan timah $(\mathrm{PCB} / \mathrm{Sn})$ dan salutan nikel ( $\mathrm{PCB} / \mathrm{Ni})$. Kajian ini memfokuskan kesan salutan permukaan ke atas perubahan pertumbuhan IMC dari segi ketebalan, kadar pertumbuhan dan tenaga pengaktifan pertumbuhan lapisan IMC.

\section{BAHAN DAN KAEDAH}

Pes aloi pateri bebas plumbum iaitu $\mathrm{Sn}-0.3 \mathrm{Ag}-0.7 \mathrm{Cu}$ (SAC 0307) dengan partikel aloi pateri berjulat sekitar 20-38 $\mu \mathrm{m}$ digunakan. Papan litar bercetak (PCB) yang digunakan bersaiz $100 \mathrm{~mm} \times 110 \mathrm{~mm} \times 1 \mathrm{~mm}$. PCB/Cu merupakan
PCB tanpa salutan digunakan sebagai sampel kawalan. Dua jenis salutan permukaan dikaji iaitu salutan timah, $\mathrm{PCB} / \mathrm{Sn}$ dan salutan nikel, $\mathrm{PCB} / \mathrm{Ni}$. Pes pateri didepositkan pada PCB menggunakan stensil dan kemudian dipaterikan melalui kaedah aliran semula pada suhu $235^{\circ} \mathrm{C}$ sehingga menghasilkan sambungan pateri dalam bentuk pepejal yang homogen. Setelah siap dipateri, ketiga-tiga jenis sampel didedahkan kepada uji kaji penuaan sesuhu pada suhu $60^{\circ} \mathrm{C}, 90^{\circ} \mathrm{C}, 125^{\circ} \mathrm{C}$ dan $150^{\circ} \mathrm{C}$ selama 1000 jam mengikut piawai JEDEC (JESD22-A103C).

Keratan rentas sampel selepas uji kaji penuaan sesuhu disediakan dengan menggunakan teknik metalografi bagi tujuan pencirian fizikal. Sampel tersebut dipotong kepada saiz $5 \mathrm{~mm} \times 3 \mathrm{~mm} \times 1 \mathrm{~mm}$. Sampel dikepil dengan menggunakan pemegang sampel dan dimasukkan bekas acuan untuk proses cagakan. Bahan cagak terdiri daripada serbuk resin pengeras (VersoCit-2 Powder, Struers) dan cecair resin epoksi (VersoCit-2 liquid, Struers) dengan nisbah berat 3:2. Serbuk resin pengeras dan cecair resin epoksi digaul perlahan-lahan di dalam cawan plastik selama $30 \mathrm{~s}$ untuk percampuran yang homogen. Kemudian, campuran ini dituang ke dalam bekas acuan dan dibiarkan mengeras pada suhu bilik dalam tempoh 4 jam. Seterusnya, sampel yang siap dicagak akan dilelas menggunakan kertas las $\mathrm{SiC}$ (Buehler) daripada gred kasar hingga kepada gred halus (800 grit, 1200 grit, 2000 grit dan 4000 grit). Proses lelasan dijalankan dengan kelajuan putaran berjulat antara 50-200 rpm. Selain itu, sampel dipusingkan pada sudut $45^{\circ}$ bagi mengelakkan sampel menjadi tidak rata. Proses akhir ialah proses penggilapan dijalankan menggunakan semburan berlian bersaiz $1 \mu \mathrm{m}$ bagi mendapatkan permukaan sampel yang bebas daripada kesan calar (Bakar et al. 2016).

Seterusnya, keadaan fizikal aloi pateri SAC 0307 pada PCB dengan salutan berbeza dikenal pasti dengan menggunakan alat pengukur fokus tidak terhingga (Alicona ${ }^{\circledR}$ ). Alat ini seakan mikroskop optik namun ianya mempunyai teknologi yang boleh menganalisis imej, profil permukaan secara 3D seperti untuk mendapatkan maklumat kekasaran, kegelombangan, isi padu, kedalaman, tekstur serta keupayaan pembesaran imej hingga $100 \times$ Dalam kajian ini, pencerapan perubahan mikrostruktur aloi pateri SAC 0307 selepas didedahkan pada penuaan sesuhu yang berbeza daripada segi ketebalan sebatian antara logam (IMC). Purata ketebalan dikira dengan mengambil bacaan ketebalan sebanyak 300 bacaan (Jalar et al. 2016). Purata ketebalan adalah berkait secara langsung dengan kadar pertumbuhan lapisan IMC akibat daripada salutan permukaan terhadap substrat $\mathrm{Cu}$.

Tenaga pengaktifan adalah tenaga yang diperlukan untuk melepasi jurang/sawar tenaga supaya tindak balas boleh berlaku (Smallman 1963). Dalam kajian ini, tenaga pengaktifan dikira adalah tenaga yang membolehkan pertumbuhan IMC berlaku dan tindak balas melibatkan proses resapan. Oleh sebab pertumbuhan IMC ini adalah proses teraktif secara terma, maka ia menuruti persamaan Arrhenius seperti berikut:

$$
x_{t}=x_{0}+\sqrt{k t}
$$


dengan $x_{t}$ ialah ketebalan IMC pada masa penuaan $t ; x_{0}$ ialah ketebalan awal lapisan IMC selepas pematerian dan adalah $k$ pemalar resapan sebagai fungsi suhu. Oleh sebab pertumbuhan IMC adalah dominan melalui proses resapan, maka persamaan Arrhenius diguna pakai. Dengan itu, tenaga pengaktifan untuk pertumbuhan IMC dikira melalui persamaan Arrhenius seperti berikut:

$$
k=k_{0} \cdot \exp \left(\frac{-Q}{R T}\right)
$$

dengan $k_{0}$ ialah pemalar pertumbuhan lapisan; $Q$ ialah tenaga pengaktifan untuk pertumbuhan lapisan IMC; $T$ ialah suhu dalam Kelvin $(\mathrm{K})$ dan $R$ ialah pemalar gas, 8.314 $\mathrm{J} / \mathrm{mol} \mathrm{K}$. Dengan menggunakan persamaan (2), tenaga pengaktifan $Q$ diperoleh daripada nilai kecerunan garis lurus plot $\ln (k)$ melawan $\left(\frac{1}{T}\right)$. Maka (2) boleh dirumuskan seperti berikut:

$$
\ln (k)=\ln \left(k_{0}\right)-\left(\frac{Q}{R T}\right)
$$

persamaan ini boleh juga dipanggil sebagai pekali resapan yang bergantung kepada suhu. Nilai tenaga pengaktifan seterusnya dianalisis untuk mengetahui aktiviti resapan yang berkait rapat dengan pertumbuhan lapisan IMC.

\section{KEPUTUSAN DAN PERBINCANGAN}

Mikrograf mikrostruktur aloi pateri SAC0307 pada PCB dengan salutan yang berbeza ditunjukkan dalam Rajah 1 . Berdasarkan pemerhatian secara kualitatif, bentuk lapisan IMC yang tumbuh adalah seperti bonggol atau scallop-like bagi semua jenis PCB. Pertumbuhan lapisan IMC kelihatan lebih nipis pada salutan $\mathrm{Ni}(\mathrm{PCB} / \mathrm{Ni})$ jika dibandingkan dengan $\mathrm{PCB} / \mathrm{Cu}$ dan $\mathrm{PCB} / \mathrm{Sn}$. Lapisan IMC selepas uji kaji penuaan sesuhu pada suhu $150^{\circ} \mathrm{C}$ selama 1000 jam (Rajah 1) telah menunjukkan terdapat dua jenis lapisan IMC yang tumbuh iaitu lapisan $\mathrm{Cu}_{6} \mathrm{Sn}_{5}$ dan lapisan $\mathrm{Cu}_{3} \mathrm{Sn}$ bagi antarasambungan aloi pateri pada $\mathrm{PCB} / \mathrm{Cu}$ (Rajah 1(a)) dan $\mathrm{PCB} / \mathrm{Sn}$ (Rajah 1(b)). Manakala, jelas kelihatan dua lapisan terbentuk pada antaramuka substrat-pateri bagi $\mathrm{PCB} / \mathrm{Ni}$ iaitu lapisan IMC dan lapisan Ni (Rajah 1(c)). Lapisan IMC yang terbentuk ialah $(\mathrm{Cu}, \mathrm{Ni})_{3} \mathrm{Sn}_{4}$ tumbuh kesan daripada salutan Ni (Gorywoda et al. 2015; Yoon \& Jung 2016). Didapati pembentukan lapisan sebatian IMC kelihatan berbeza akibat daripada pengaruh salutan permukaan. Sebagai contoh, lapisan IMC jenis $\mathrm{Cu}_{3} \mathrm{Sn}_{5}$ (4) dan $\mathrm{Cu}_{6} \mathrm{Sn}_{5}$ (5) (Afolabi et al. 2015) biasa terhasil pada antaramuka aloi pateri dan substrat $\mathrm{Cu}$. Manakala dengan salutan $\mathrm{Ni},(\mathrm{PCB} / \mathrm{Ni}$ ) lapisan IMC yang tumbuh ialah $(\mathrm{Cu}, \mathrm{Ni})_{3} \mathrm{Sn}_{4}$ (6) (Yoon et al. 2015; Zeng et al. 2016).

$$
\begin{aligned}
& 3 \mathrm{Cu}+5 \mathrm{Sn} \rightarrow \mathrm{Cu}_{3} \mathrm{Sn}_{5} \\
& 5 \mathrm{Sn}+6 \mathrm{Cu} \rightarrow \mathrm{Cu}_{6} \mathrm{Sn}_{5} \\
& 3 \mathrm{Cu}+3 \mathrm{Ni}+4 \mathrm{Sn} \rightarrow\left(\mathrm{Cu}, \mathrm{Ni}_{3} \mathrm{Sn}_{4}\right.
\end{aligned}
$$

Ketebalan lapisan IMC semakin meningkat seiring dengan peningkatan suhu uji kaji penuaan sesuhu (Rajah 2) adalah disebabkan oleh tenaga terma yang menyebabkan resapan antara pateri, substrat $\mathrm{Cu}$ dan antaramuka IMC semasa uji kaji penuaan yang berbeza. Purata ketebalan lapisan IMC adalah sebanyak $3.3 \mu \mathrm{m}$ sebelum uji kaji penuaan sesuhu dan meningkat kepada $9.0 \mu \mathrm{m}$ selepas uji kaji penuaan sesuhu pada suhu $150^{\circ} \mathrm{C}$ selama 1000 jam bagi $\mathrm{PCB}$ tanpa salutan $(\mathrm{PCB} / \mathrm{Cu})$. Manakala $\mathrm{PCB}$ dengan
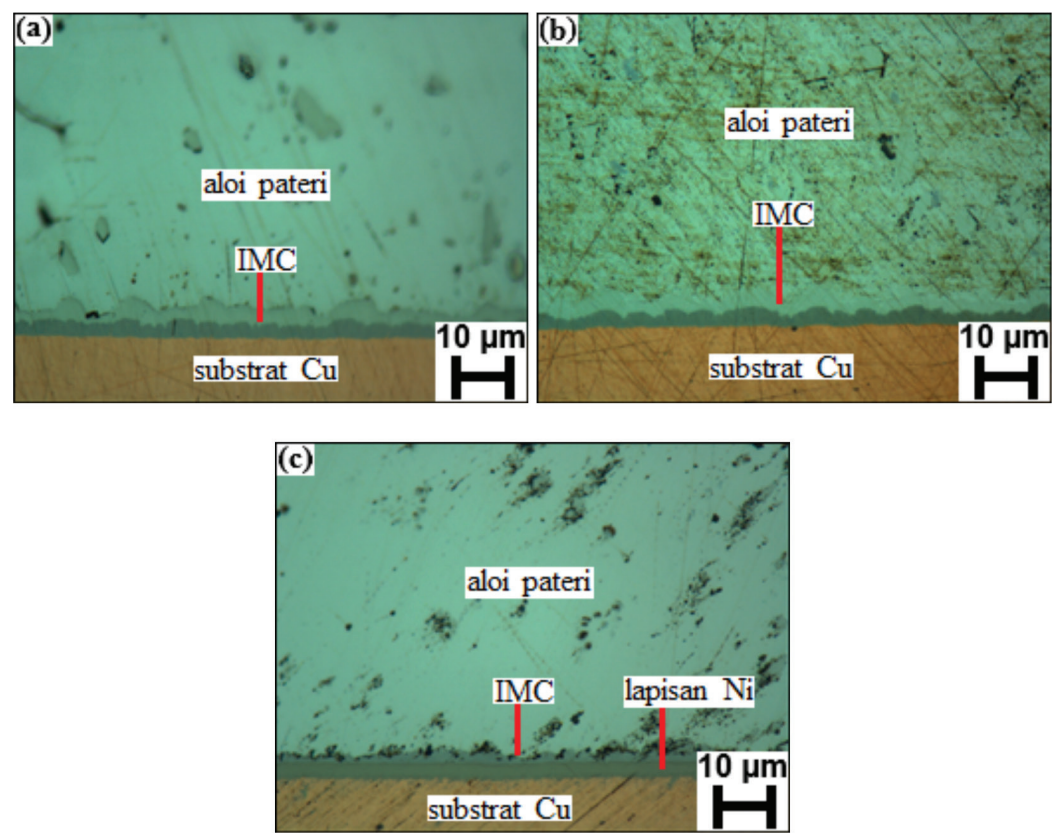

RAJAH 1. Mikrograf bagi SAC 0307 pada: (a) PCB/Cu, (b): PCB/Sn dan (c) PCB/Ni selepas uji kaji penuaan sesuhu pada $150^{\circ} \mathrm{C}$ selama 1000 jam 


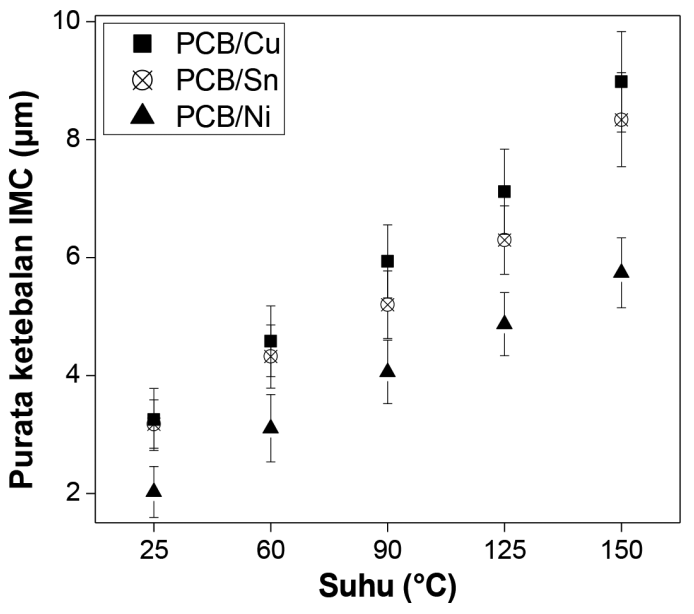

RAJAH 2. Purata ketebalan IMC bagi SAC 0307 pada PCB berbeza selepas uji kaji penuaan sesuhu berbeza selama 1000 jam

salutan $\mathrm{Sn}(\mathrm{PCB} / \mathrm{Sn})$ pula, ketebalan lapisan IMC sebanyak $3.3 \mu \mathrm{m}$ telah meningkat kepada $8.3 \mu \mathrm{m}$ selepas uji kaji penuaan sesuhu pada suhu $150^{\circ} \mathrm{C}$. Ketebalan lapisan IMC yang terendah dicatatkan dengan salutan $\mathrm{Ni}$ (PCB/ $\mathrm{Ni}$ ) iaitu daripada $2.0 \mu \mathrm{m}$ kepada $5.7 \mu \mathrm{m}$ selepas uji kaji penuaan sesuhu pada suhu $150^{\circ} \mathrm{C}$. Perbezaan ketebalan lapisan IMC dengan salutan $\mathrm{Ni}$ adalah sangat ketara dan keputusan ketebalan lapisan IMC kajian ini adalah selaras dengan kajian Lee et al. (2015) yang melaporkan tentang salutan $\mathrm{Ni}$ bertindak untuk menghalang resapan atom $\mathrm{Cu}$ ke dalam aloi pateri $\mathrm{Sn}-58 \mathrm{Bi}$. Hal ini adalah daripada tindakan lapisan $\mathrm{Ni}$ daripada kemasan permukaan yang bertindak sebagai lapisan sawar yang melambatkan peresapan atom $\mathrm{Cu}$ untuk membentuk lapisan IMC. Sehubungan dengan itu, salutan Ni mampu mengawal pertumbuhan lapisan IMC.

Berikutan daripada keputusan pertumbuhan lapisan IMC tersebut telah menghasilkan tenaga pengaktifan yang lebih tinggi bagi PCB yang mempunyai salutan permukaan (Sn dan Ni). Ini adalah sering dengan keputusan kadar pertumbuhan lapisan IMC (Rajah 3) yang paling rendah pada salutan Ni berbanding PCB dengan salutan Sn dan tanpa salutan. Analisis lanjutan terhadap pertumbuhan lapisan IMC boleh dijelaskan dengan tenaga pengaktifan, Q melalui plot Arrhenius bagi pertumbuhan lapisan IMC SAC0307 pada PCB dengan salutan berbeza selepas uji kaji penuaan seperti di dalam Rajah 4. Didapati tenaga pengaktifan bagi pertumbuhan IMC pada $\mathrm{PCB} / \mathrm{Cu}$ ialah $38 \mathrm{~kJ} / \mathrm{mol}, 39 \mathrm{~kJ} / \mathrm{mol}$ pada $\mathrm{PCB} / \mathrm{ImSn}$ dan $41 \mathrm{~kJ} / \mathrm{mol}$ pada $\mathrm{PCB} / \mathrm{Ni}$. Nilai ketebalan serta kadar pertumbuhan lapisan IMC yang rendah adalah selaras dengan tenaga pengaktifan yang tinggi. Tenaga pengaktifan yang tinggi ini menyebabkan lapisan IMC tumbuh lebih perlahan pada $\mathrm{PCB} / \mathrm{Ni}$ jika dibandingkan dengan $\mathrm{PCB} / \mathrm{Cu}$ dan $\mathrm{PCB} / \mathrm{Sn}$ yang mempunyai tenaga pengaktifan yang lebih rendah (maka lapisan IMC lebih mudah untuk tumbuh). Hubungan antara nilai ketebalan atau kadar pertumbuhan IMC dan tenaga pengaktifan menunjukkan bahawa salutan $\mathrm{Ni}$ $(\mathrm{PCB} / \mathrm{Ni})$ boleh membantu dalam mengawal atau dapat

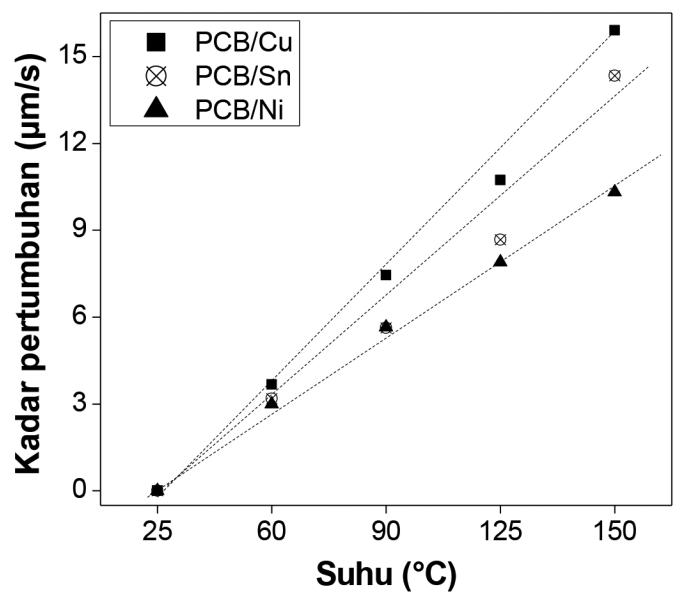

RAJAH 3. Kadar pertumbuhan IMC bagi SAC 0307 pada PCB berbeza selepas uji kaji penuaan sesuhu berbeza selama 1000 jam

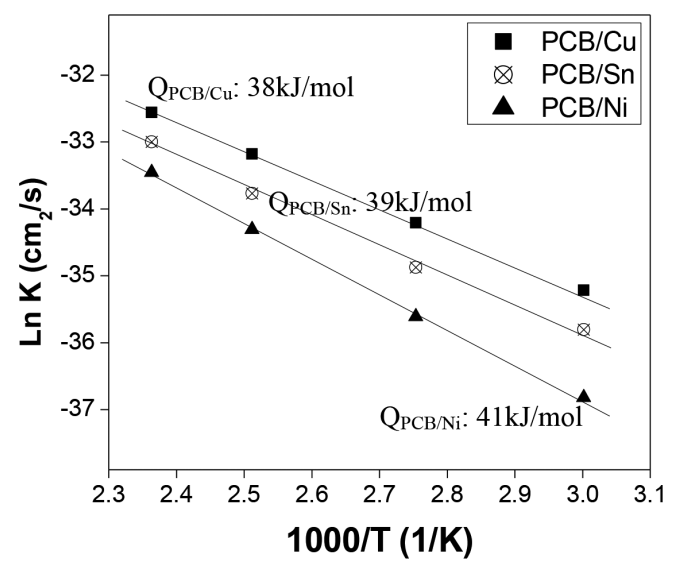

RAJAH 4. Plot Arrhenius bagi pertumbuhan lapisan IMC SAC 0307 pada PCB dengan salutan berbeza selepas uji kaji penuaan

menghasilkan IMC yang lebih nipis berbanding dengan $\mathrm{PCB} / \mathrm{Cu}$ dan $\mathrm{PCB} / \mathrm{Sn}$. Keputusan kajian ini adalah selari dengan kajian oleh Choubey et al. (2008) yang melaporkan pertumbuhan IMC aloi pateri $\mathrm{Sn} 3.5 \mathrm{Ag}$ adalah lebih rendah dengan salutan permukaan Ni berbanding dengan ImSn, ImAg dan OSP. Keputusan kajian ini juga menunjukkan bahawa tenaga pengaktifan pertumbuhan IMC SAC 0307 pada PCB dengan salutan berbeza yang diperoleh adalah selaras dengan keputusan tenaga pengaktifan pertumbuhan IMC bagi aloi pateri $\mathrm{Sn}-\mathrm{Ag}-\mathrm{Cu}$ dalam julat $47-103 \mathrm{~kJ} / \mathrm{mol}$ dalam kajian-kajian lepas (Tseng \& Duh 2013; Xu et al. 2005; Yang et al. 2014).

\section{KESIMPULAN}

Salutan Ni (PCB/Ni) telah memberikan kesan ke atas pertumbuhan lapisan IMC dengan menghasilkan ketebalan IMC yang jauh lebih nipis $\sim 5.7 \mu \mathrm{m}$ berbanding PCB/ $\mathrm{Cu}$ dan $\mathrm{PCB} / \mathrm{Sn}$, iaitu sekitar $8-9 \mu \mathrm{m}$ selepas uji kaji penuaan sesuhu pada $150^{\circ} \mathrm{C}$ selama 1000 jam. Tenaga 
pengaktifan yang tinggi ini menyebabkan lapisan IMC tumbuh perlahan berbanding dengan $\mathrm{PCB} / \mathrm{Cu}$ dan $\mathrm{PCB} /$ ImSn dengan tenaga pengaktifan yang lebih rendah 38-39 $\mathrm{kJ} / \mathrm{mol}$. Salutan Ni dapat mengawal ketebalan IMC yang lebih baik berbanding salutan Ni dan PCB tanpa salutan dengan kadar pertumbuhan lapisan IMC paling rendah dan selaras dengan tenaga pengaktifan tertinggi iaitu $41 \mathrm{~kJ} /$ mol. Pertumbuhan lapisan IMC yang perlahan dan terkawal dapat meningkatkan kebolehharapan dan jangka hayat sambungan pateri dalam pempakejan elektronik.

\section{PENGHARGAAN}

Penulis merakamkan penghargaan kepada pihak RedRing Solder (M) Sdn. Bhd. atas kolaborasi projek ini serta sumbangan bahan penyelidikan, Universiti Kebangsaan Malaysia (UKM) dan Kementerian Pendidikan Tinggi atas geran penyelidikan FRGS/1/2017/STG07/UKM/01/3.

\section{RUJUKAN}

Afolabi, T.T.D., Hanim, M.A.A., Norkhairunnisa, M., Yusoff, H.M. \& Suraya, M.T. 2015. Growth kinetics of intermetallic layer in lead-free $\mathrm{Sn}-5 \mathrm{Sb}$ solder reinforced with multi-walled carbon nanotubes. Journal of Materials Science: Materials in Electronics 26(10): 8249-8259.

Bakar, M.A., Jalar, A., Daud, A.R., Ismail, R., Lah, N.A.C. \& Ibrahim, N.S. 2016. Nanoindentation approach on investigating micromechanical properties of joining from green solder materials. Sains Malaysiana 45(8): 1275-1279.

Bui, Q.V., Nam, N.D., Choi, D.H., Lee, J.B., Lee, C.Y., Kar, A., Kim, J.G. \& Jung, S.B. 2010. Corrosion protection of ENIG surface finishing using electrochemical methods. Materials Research Bulletin 45(3): 305-308.

Chen, B.L. \& Li, G.Y. 2004. Influence of Sb on IMC growth in $\mathrm{Sn}-\mathrm{Ag}-\mathrm{Cu}-\mathrm{Sb} \mathrm{Pb}$-free solder joints in reflow process. Thin Solid Films 462-463: 395-401.

Chen, Y.H., Wang, Y.Y. \& Wan, C.C. 2007. Microstructural characteristics of immersion tin coatings on copper circuitries in circuit boards. Surface \& Coatings Technology 202: 417424.

Choubey, A., Yu, H., Osterman, M., Pecht, M., Yun, F., Yonghong, L. \& Ming, X. 2008. Intermetallics characterization of lead-free solder joints under isothermal aging. Journal of Electronic Materials 37(8): 1130-1138.

Fallahi, H., Nurulakmal, M.S., Arezodar, F. \& Abdullah, J. 2012. Effect of iron and indium on IMC formation and mechanical properties of lead-free solder. Materials Science and Engineering A 553: 22-31.

Gorywoda, M., Dohle, R., Wirth, A., Burger, B. \& Gobler, J. 2015. On the failure mechanism in lead-free flip-chip interconnects comprising enig finish during electromigration. 2015 IEEE 65th Electronic Components and Technology Conference (ECTC).pp. 2030-2035.

Jalar, A., Bakar, M.A., Ismail, R. \& Daud, A.R. 2016. Statistical aspect on the measuring of intermetallic compound thickness of lead free solders. Journal of Scientific Research and Development 3(4): 49-54.

Kao, C.L. \& Chen, T.C. 2018. Ball impact responses of Sn$1 \mathrm{Ag}-0.5 \mathrm{Cu}$ solder joints at different temperatures and surface finishes. Microelectronics Reliability 82: 204-212.
Kim, K.H., Koike, J., Yoon, J.W. \& Yoo, S. 2016. Effect of plasma surface finish on wettability and mechanical properties of sac305 solder joints. Journal of Electronic Materials 45(12): 6184-6191.

Lee, T.K., Bieler, T.R., Kim, C.U.\& Ma, H. 2015. Fundamentals of Lead-Free Solder Interconnect Technology: From Microstructures to Reliability. San Jose: Springer.

Lin, C.P. \& Chen, C.M. 2012. Solid-state interfacial reactions at the solder joints employing $\mathrm{Au} / \mathrm{Pd} / \mathrm{Ni}$ and $\mathrm{Au} / \mathrm{Ni}$ as the surface finish metallizations. Microelectronics Reliability 52(2): 385-390.

Lin, J., Wang, C., Wang, S., Chen, Y., He, W. \& Xiao, D. 2016. Initiation electroless nickel plating by atomic hydrogen for PCB final finishing. Chemical Engineering Journal 306: $117-123$.

Smallman, R.E. 1963. Modern Physical Metallurgy. Edisi ke-2. Belfast: Butterworth \& Co.

Nishikawa, H. \& Iwata, N. 2015. Formation and growth of intermetallic compound layers at the interface during laser soldering using $\mathrm{Sn}-\mathrm{Ag} \mathrm{Cu}$ solder on a $\mathrm{Cu} \mathrm{Pad}$. Journal of Materials Processing Technology 215: 6-11.

Sundelin, J.J., Nurmi, S.T., Lepist, T.K. \& Ristolainen, E.O. 2006. Mechanical and microstructural properties of $\mathrm{SnAgCu}$ solder joints. Materials Science and Engineering A 420: 55-62.

Tseng, C.F. \& Duh, J.G. 2013. The influence of Pd on growth behavior of a quaternary $(\mathrm{Cu}, \mathrm{Ni}, \mathrm{Pd})_{6} \mathrm{Sn}_{5}$ compound in $\mathrm{Sn}$ 3.0Ag-0.5Cu/Au/Pd/Ni-P solder joint during a liquid state reaction. Journal of Materials Science 48(2): 857-865.

Xu, L., Pang, J.H.L. \& Che, F.X. 2005. Intermetallic growth and failure study for sn-ag-cu/enig pbga solder joints subject to thermal cycling. Electronic Components and Technology Conference. pp. 682-686.

Yan, L., Xiao, K., Yi, P., Dong, C., Wu, J., Bai, Z., Mao, C., Jiang, L. \& Li, X. 2017. The corrosion behavior of PCB-ImAg in industry polluted marine atmosphere environment. Materials \& Design 115: 404-414.

Yi, P., Xiao, K., Dong, C., Zou, S. \& Li, X. 2018. Effects of mould on electrochemical migration behaviour of immersion silver finished printed circuit board. Bioelectrochemistry 119: 203-210.

Yang, Z.J., Yang, S.M., Yu, H.S., Kang, S.J., Song, J.H. \& Kim, K.J. 2014. IMC and creep behaviour in lead-free solder joints of Sn-Ag and Sn-Ag-Cu alloy system by SP method. International Journal of Automotive Technology 15(7): 1137-1142.

Yoon, J.W. \& Jung, S.B. 2016. Effect of hygrothermal treatment on reliability of thermo-compression bonded $\mathrm{FPCB} / \mathrm{RPCB}$ contact joints. Materials Transactions 57(5): 716-720.

Yoon, J.W., Bang, J.H., Lee, C.W. \& Jung, S.B. 2015. Interfacial reaction and intermetallic compound formation of $\mathrm{Sn}-1 \mathrm{Ag} /$ ENIG and Sn-1 Ag/ENEPIG solder joints. Journal of Alloys and Compounds 627: 276-280.

Zeng, G., McDonald, S.D., Mu, D., Terada, Y., Yasuda, H., Gu, Q., Salleh, M.A.A.M. \& Nogita, K. 2016. The influence of ageing on the stabilisation of interfacial $(\mathrm{Cu}, \mathrm{Ni})_{6}(\mathrm{Sn}, \mathrm{Zn})_{5}$ and $(\mathrm{Cu}, \mathrm{Au}, \mathrm{Ni})_{6} \mathrm{Sn}_{5}$ intermetallics in Pb-free Ball Grid Array (BGA) solder joints. Journal of Alloys and Compounds 685: 471-482.

Zhang, Q.K. \& Zhang,Z.F. 2011.In-situ observations on fracture behaviors of Cu-Sn IMC layers induced by deformation of $\mathrm{Cu}$ substrates. Materials Science and Engineering A 530: 452-461. 
Maria Abu Bakar \& Azman Jalar*

Institute of Microengineering and Nanoelectronics

Universiti Kebangsaan Malaysia

43600 UKM Bangi, Selangor Darul Ehsan

Malaysia

Azman Jalar*

School of Applied Physics

Faculty of Science and Technology

Universiti Kebangsaan Malaysia

43600 UKM Bangi, Selangor Darul Ehsan

Malaysia

Mohd Zulkifly Abdullah

School of Aerospace Engineering

Universiti Sains Malaysia, Engineering Campus

314300 Nibong Tebal

Seberang Perai Selatan, Pulau Pinang

Malaysia
Najib Saedi Ibrahim \& Mohd Ariffin Ambak

Redring Solder (M) Sdn. Bhd.

Lot 17486, Jalan Dua, Taman Selayang Baru

68100 Batu Caves, Selangor Darul Ehsan

Malaysia

*Pengarang untuk surat-menyurat; email: azmn@ukm.edu.my

Diserahkan: 31 Mac 2018

Diterima: $\quad 15$ Mei 2018 